\title{
Cultural Adaptation and Open Pilot of Meaning-Centered Psychotherapy for Puerto Rican Patients with Advanced Cancer
}

\author{
Normarie Torres-Blasco ${ }^{1, ~ *}$, Eida Castro-Figuero ${ }^{1,2}$, Olga Garduño-Ortega ${ }^{3}$, \\ Rosario Costas-Muñiz ${ }^{3,4}$ \\ ${ }^{1}$ Ponce Research Institute, School of Behavioural and Brain Sciences, Ponce Health Sciences University, Ponce, Puerto Rico \\ ${ }^{2}$ Department of Psychiatry, School of Medicine, Ponce Health Sciences University, Ponce, Puerto Rico \\ ${ }^{3}$ Department of Psychiatry and Behavioural Sciences, Memorial Sloan Kettering Cancer Center, New York, United States \\ ${ }^{4}$ Department of Psychiatry, Weill Cornell Medical College, New York, United States
}

Email address:

normarietorres@psm.edu (N. Torres-Blasco)

${ }^{*}$ Corresponding author

\section{To cite this article:}

Normarie Torres-Blasco, Eida Castro-Figuero, Olga Garduño-Ortega, Rosario Costas-Muñiz. Cultural Adaptation and Open Pilot of Meaning-Centered Psychotherapy for Puerto Rican Patients with Advanced Cancer. Science Journal of Education .

Vol. 8, No. 4, 2020, pp. 100-107. doi: 10.11648/j.sjedu.20200804.12

Received: June 29, 2020; Accepted: July 15, 2020; Published: August 25, 2020

\begin{abstract}
In Puerto Rico, cancer incidence increases significantly, and is accompanied with a greater risk of experiencing high levels of depressive symptoms, emotional distress, and reduced quality of life when compared to other minority ethnic groups. Studies suggest that interventions to attend distress in Latino patient population would benefit from including components that seek to improve patients' spiritual well-being. The purpose of this study is to identify the level of comprehension and acceptance of Meaning-Centered Psychotherapy (MCP) concepts. A mixed method design was conducted with in-depth interviews and open pilot data. A total of nine participants with advanced or metastatic cancer were sampled from an Oncology Clinic in the south of Puerto Rico. Six semi-structured interviews and six ethnographic notes with audiotape sessions were selected and transcribed. All material was analyzed, resulting in a sample of six semi-structured interview and six ethnographic note peer sessions. Patients showed low comprehension of the MCP concepts of meaning, the finite, and legacy. Patients showed low acceptance of death and its related concepts. They also reported high acceptance of integrating family members to their therapy. In order to tailor the intervention and improve comprehension, the content should include examples, shorter questions, and brief definitions. Additionally, there is a need to address death and its related concepts in end of life.
\end{abstract}

Keywords: Puerto Ricans, Cultural Adaptation, Advanced Cancer, Meaning Centered

\section{Introduction}

\subsection{Puerto Rican Cancer Patients}

Puerto Ricans are the second largest and fastest-growing Latino minority group in the U.S. In 2016, 57.5 million Latinos represented $17.8 \%$ of the 323 million population in the United States, and another 3.4 million citizens living in Puerto Rico [1]. Cancer incidence increased significantly in Puerto Rico between 2007 and 2011, with cancer becoming the first cause of death among the adult population in the island [2]. This already high cancer incidence is accompanied by the even higher risk in Latinos of experiencing elevated levels of depressive symptoms, emotional distress, and reduced quality of life when compared to other minority ethnic groups [3, 4]. Further, per our recent systematic review, a lack of participation of Latinos, including Puerto Ricans, on the development of psychosocial intervention was found [4-22].

\subsection{Existential Distress Among Latino Cancer Patients}

Spirituality and meaning-making are resources that support resilience and help improve the quality of life of Latino patients with cancer [23]. The psychosocial needs of Latino 
cancer patients are critical components of cancer care across the illness trajectory $[24,25,26]$. Literature documents a high prevalence of emotional distress in Latinos, particularly anxiety, before chemotherapy initiation. It also identifies several demographic and clinical factors associated with increased risk for heightened distress. In multi-ethnic research, Latina breast cancer survivors reported more emotional distress and related concerns than Black and non-Hispanic White women [27]. Additionally, studies suggest that interventions to address distress in Latino patient population would benefit from including components that seek to improve patients' spiritual well-being [28]. In fact, a positive correlation has been described between high levels of spirituality and health-related quality of life (QOL) [29].

\subsection{Existential Distress Among Latino Cancer Patients}

The Meaning Centered psychotherapy (MCP) is an empirically based treatment shown to significantly reduce psychological distress while increasing spiritual well-being and a sense of meaning and purpose in the life of advanced cancer patients. Randomized control trials (RCTs) of MCP in both individual and group formats have demonstrated significant improvement in spiritual well-being, quality-of-life, and a significant decrease in depression, hopelessness, and desire for death in advanced cancer patients [17, 30, 31]. However, this intervention is not yet adapted for racial and ethnic minority populations for whom the concept of "meaning" may likely differ from that of westernized White societies.

\subsection{Cultural Adapted Interventions}

There is a need for cultural adapted psychosocial intervention for advanced cancer patients. One of the first frames is the Ecological Validity Model (EVM), which delineates eight dimensions to consider in the development of a cultural adaptation [32, 33, 34]. This framework has been used to adapt cognitive behavioral therapy and interpersonal therapy for Puerto Rican adolescents [35], as well as used in parent-child interaction therapy [36]. It was found that adapted therapies are useful in both randomized studies and pilot investigations. This study was designed to identify the level of comprehension and acceptability of Meaning-Centered Psychotherapy (MCP) among advanced cancer patients in Puerto Rico, as part of an international collaboration of adapting MCP for Latinos.

\section{Method}

\subsection{Study Design and Procedure}

A mixed-method, concurrent, and integrative approach was used for this study. Quantitative and qualitative data were collected from Latino patients with advanced cancer in phase one and two. The methods or therapeutic strategies used in this study were conducted based on the suggestion of cultural adaptation literature $[32,33,34]$ and a $2011 \mathrm{NIH}$ report on the best practices for mixed method research [37]. Both have highlighted the need for inclusion of both qualitative and quantitative approaches to develop and test interventions. The proposed study is described as a cross-sectional convergent design and will use both quantitative and qualitative approaches.

\subsection{Setting}

Participants in the study were recruited from a private oncology clinic in Ponce, Puerto Rico, referred by the oncologist. The research protocol was submitted to the Authorization of the Institutional Review Board (IRB) of the Ponce Health Sciences University. We divided the protocol into three methodological phases. In the first phase, semi-structured interviews and comprehensive scaled assessment data were administered. In the second phase, ethnographic notes and quantitative pre-test and post-test data comprehensive scaled assessment were administered. Finally, for the third phase, the results of the first and second phase were integrated with the triangulation of results.

After the participants consented to participate in the study, the distress thermometer (DT) screening tool was administered, a scaled normed to the Latino population [38]. After completing the DT, participants were invited to complete a more comprehensive scaled assessment made for the Latino population, which included spiritual well-being [39] and quality of life scales (Functional Assessment of Cancer Therapy-General) [40].

\subsection{Sampling Strategy}

During the first phase, after completing the informed consent and comprehensive scaled assessment, the in-depth interviews with six advanced cancer patients were conducted. The objective in phase one was to explore the comprehension and acceptance of the concepts and intervention questions of MCP. In phase two, after completing the informed consent and the comprehensive scaled assessment (DT $>6$ ), the participants were invited to participate in the Meaning Centered Psychotherapy intervention. They were informed that therapy sessions would be audio-recorded and ethnographic notes would be made. The interventionist took ethnographic notes and reviewed them with the recorded material during the open pilot with six Puerto Rican patients (three patients of phase one and three new patients recruit for phase two). The objective in phase two was to explore the comprehension and acceptance of the concepts and intervention questions of MCP and to explore psychological clinical changes in the patients.

In the third phase, the analyzes of phase one and two were compared. After comparing and relating the information from the previous phases, the interpretation of the findings of this investigation was made. The adaptation plan included the technique of ethnographic notes focused on the comprehension and acceptability of the MCP intervention content and concepts.

\subsection{Data Analysis}

The first and second phase of this study consisted in the collection and analysis of qualitative (semi-structured interviews and ethnographic notes) and quantitative data (questionnaires) in a parallel manner regarding patients with advanced stage cancer in Puerto Rico. Frequency analyzes and 
descriptive statistics were performed for sociodemographic data and instruments, through measures of central tendency and variation. For the qualitative analysis of the semi-structured interviews and ethnographic notes were transcribed into a word processor (Microsoft Word). After the transcription process, they were analyzed by coding in Microsoft Word and the qualitative data were analyzed with deductive content analysis.

The semi-structured interview and ethnographic note taking technique contained information that evaluated the comprehension and acceptance of the concepts of the intervention. Responses were classified using two generated matrixes based on acceptability and comprehension. A content analysis was performed for the semi-structured interview and ethnographic note by at least-three independent coders using an inductive coding matrix. During the intervention, the content was re-phrased and examples were provided to explain the concepts of MCP.

To determine the comprehension of the concepts of MCP therapy, it was classified into clear, moderate, low, and ambiguous compression. The concepts that were classified with clear comprehensions were those in which the participants could provide a response that fulfilled the concrete and profound aspect of the concept. Regarding the classification of a moderate comprehension, this category was assigned to all those defined concretely without deepening the concept. Concurrently, the category of low comprehension was assigned to the concepts in which the participants reported not understanding at the time of issuing a response; it was not similar to the conventional definition of the concept.

The category of ambiguous acceptance was created for the case when the concept was not clear for the participants. To determine the acceptance of the concepts of MCP therapy, it was classified into high, moderately low, and ambiguous acceptability. Those classified with high acceptability were reported as acceptable by the participants. Regarding moderate acceptability, this category was assigned to all concepts in which the participants did not show high or low acceptability. At the same time, the category of low acceptability was assigned to the concepts reported by the participants as unacceptable content.

After completing phases one and two, the analysis of the qualitative (semi-structured interviews and ethnographic notes) and quantitative (questionnaire results phase one and pre-and post-intervention evaluation) data collections were joined. In this phase three, the team compared and related the findings of the previous phases, with the purpose of interpreting how Puerto Rican patients with advanced cancer perceive the topics associated with Individual Psychotherapy focused on meaning. These steps allowed the researchers to begin establishing categories that more explicitly reflected the understanding and acceptability of the concepts of MCP therapy. The recommendations suggested by participants through the semi-structured interviews and open pilot were considered. The triangulation in this research consisted of the following: comprehension and acceptance of the concepts of MCP psychotherapy in all phases of the project, to examine the agreement of the findings that were ongoing, and the incursion of external colleagues offering feedback on the analysis and conclusions.

\section{Results}

\subsection{Sample Characteristics}

The six participants of phase one were between the ages of 52 and 76 years. The majority were married men $(83.3 \%)$. The level of education was below $\leq$ High School (66.7\%) and the majority were retired (83.3\%). For phase two, the participants' ages ranged from 46 to 78 years. Regarding the marital status of the participants, $50 \%$ reported being married. The level of education was below $\leq$ High School $(66.7 \%)$ and the majority were retired $(66.7 \%)$. The participants presented different types of cancer; the most common cancer diagnoses in phase one was stomach and neoplasm. In phase two, it was stomach.

\subsection{Findings}

During the semi-structured interview, the participants were asked for their feedback on comprehension of the topics related to the intervention. Table 2 shows some of the emergent concepts regarding comprehension in the semi-structured interviews and ethnographic notes. The emergent reaction in each concept is described and illustrated below with representative quotes (see Table 1 for an overview and description of the themes). The participants showed low comprehension in: Legacy and Finite. Findings suggested moderate comprehension in identity and connecting with life. Furthermore, the participants reported high comprehension of the concepts: Creative sources of meaning, experiential sources of meaning, and transitions.

Table 1. Comments of intervention.

\begin{tabular}{lll}
\hline Coding & Concept & Themes \\
\hline \multirow{2}{*}{ Low Comprehension } & Legacy & 1. Survivorship \\
& & 2. Overcome adversity \\
& Finite & 1. Life limitation \\
& & 2. Not permanent \\
& 1. roles \\
Moderate Comprehension & 2. relationships \\
& Identity & 3. legacies \\
& & 4. values \\
& 1. Beauty \\
& Connecting with life & 2. Humor \\
& & 3. Love \\
\hline
\end{tabular}




\begin{tabular}{lll}
\hline Coding & Concept & Themes \\
\hline High & & 1. work \\
Comprehension & Creative Sources of Meaning & 2. parenting \\
& & 3. hobbies \\
& & 1. Love \\
& & 2. Beauty \\
& Experiential Sources of Meaning & 3. Art \\
& & 4. Nature \\
& & 5. Humor \\
& 1. Transitions \\
& Transitions & 2. Reflections \\
\hline
\end{tabular}

\subsubsection{Low Comprehension}

Non-reflective about the concepts of Legacy and Finite. This concept was observed with low comprehension. One of the participants discussed the concept of legacy as follows:

"Well, we must continue to survive all adversities while God gives us life." Translation of: "Pues, que hay que seguir sobreviviendo a todas las adversidades mientras Dios nos de vida". P2

These statements present a sense of non-reflectiveness regarding the concept of Legacy. This participant emphasized the importance of survivorship and overcoming adversity without connecting the concept of legacy, which refers to: 1) the inheritance of material and non-material things that we receive. Legacy could be biological/genetic, family, cultural heritage, family values, virtue, etc., 2) at the same time, we build a legacy through our lives, and 3) we will pass on a legacy, in the future, to our loved ones and to those who knew us.

Other individuals presented low comprehension in the concept of finite in the semi-structured interview:

"No, life is so finite that it looks like a funnel, as I told you, little one. That's how finite it is, it's very wide and at the moment it gets narrow." Translate of: "No, la vida es tan finita que parece un embudo, como te dije orita. Así de finito es, es bien ancho y de momento se pone estrecha." P5 Also, this statement presents a sense of non-reflectiveness about the concept of Finite. This participant emphasized in the aspect of the measure of finite and don't make the connection of the concept that we encountered life limitation and limits.

\subsubsection{Moderate Comprehension}

Recognition of the concept. There was acknowledgment of the identity concepts. As one of the participants expressed:

"Well I am XX, son of my mother, father of my children, and husband of $X X$." Translation of: "Pues yo soy $X X$, hijo de mi madre, padre de mis hijos y esposo de XX”. P1

This statement presents a sense of a moderate comprehension about the concept of identity. The participant emphasized on his own description and did not connect other aspects of identity such as: it is made up of roles, legacies, and values. These are the sources of meaning in one's life. To reflect on the sources of meaning in each person's life, it is important to start with your own understanding of who you are.

This moderate recognition was also presented in the concept of connecting with life, as one of the participants reports:

Patient reported after re-phase and examples: "Since the diagnosis of cancer, it is very difficult to perform many things that I previously enjoyed". Translation of: "Desde el diagnóstico de cáncer se me está haciendo muy difícil realizar muchas cosas que antes gozaba”. P8

This statement presents a moderate comprehension regarding the concept of connecting with life. This participant emphasized on the cancer diagnosis and how the disease has limited him from doing the things he loves the most. However, the participant failed to associate the part of connecting with life through beauty, humor, and love.

\subsubsection{High Comprehension}

This high comprehension was presented in the concept of overcoming adversity and relationships as the participant reports:

"When I built my house by myself alone, it took me years, little by little. But now I've done two." Translation of: "Cuando hice la casa yo mismo solo. Me tardé años, poco a poco. He hecho dos. " P3

"The diagnosis of cancer has helped me feel and be better with myself and with God." Translation of: "El diagnóstico de cáncer me ha ayudado a sentirme y a estar mejor conmigo mismo y con Dios". P4

"I liked this process and I am very grateful for this". Translation of: "Me gustó este proceso y estoy bien agradecido por esto”. P8

\subsubsection{Acceptance}

During the semi-structured interview and ethnographic notes, the participants evaluated the acceptance of the topics related to the intervention. Table 2 shows some of the expressions made by them regarding the acceptance of the intervention. They showed low acceptance in the concepts death and dying. Findings suggested moderate acceptance in identity and connecting with life. Moreover, the participants reported high acceptance of integrating their family to therapy.

Table 2. Acceptance of intervention.

\begin{tabular}{ll}
\hline Coding & Concepts \\
\hline Low Acceptance & Death and dying \\
Moderate Acceptance & Connecting with life \\
High Acceptance & Family \\
\hline
\end{tabular}

\subsubsection{Low Acceptance}

Non-acceptance about death. This concept was observed as non-accepted in participants. Three participants with 
advanced cancer reported the following:

"I do not understand the reason for that question. No, I do not like it and I do not think others want to talk about it." Translation of: "No entiendo el porqué de esa pregunta. No, no me gusta y no creo que otros quieran hablar de eso". P5

"I don't want to talk about this." Translation of: "Yo no quiero hablar de eso". P7

"This question took me by surprise, it seems strong."

Translation of: "Esta pregunta me tomó por sorpresa, me parece fuerte". $P 8$

These statements described an unlikelihood regarding the concept of death and dying. Also, a participant emphasized the importance of not understanding "the need of asking these questions". The participants reported that other patients will not be able to talk about questions involving death and dying:

"I do not think other patients want to talk about these [referring to death] questions". Translation of: "No creo que otros pacientes quieran hablar de estas preguntas [refiriendose a la muerte]". $P 3$

\subsubsection{Moderate Acceptance}

Moderate acceptance about connecting with life. This concept was observed as moderately accepted by participants. Two participants with advanced cancer reported the follow:

"Yes, it is acceptable. I understood it, but after you explained it to me". Translation of: "Sí, es aceptable. Sí la entendi, pero después de que me la explicaste" P4

"I liked it, but when you explained it to me differently". Translation of: "Me gusto, pero cuando me lo explicaste diferente" $P 8$

These statements reported moderate acceptance of the concept connecting with life. These participants emphasized the importance of re-phrasing the concept to have a better understanding.

\subsubsection{High Acceptance}

High acceptance

The participants reported a high acceptance involving the integration of family members to the psychological treatment. The participants suggested:

"I would have liked a session with my relatives". Translation of: "Me hubiera gustado una sesión con mis familiares". P1 "I would have liked to include my husband". Translation of: "Yo hubiese querido incluir a mi esposo". P5

"It would have been good to include my children". Translation of: "Yo hubiese sido bueno incluir a mis hijos".

"Hubiese sido bueno incluir a mis hijos". P7

"For my family it is important, and I would have liked them to be here with me." Translation of: "Para mi familia es importante y me hubiera gustado que estuvieran aqui conmigo". $P 8$

\section{Discussion}

Spirituality, sources of meaning, and family integration to therapy may help Latino cancer patients cope with the many related psychological elements of emotional distress, as well as frame unique opportunities for intervention during their causal origin through an exploration of meaning [23]. The findings in this study suggest that Meaning Centered Psychotherapy (MCP) is a feasible psychotherapy for Latino patients who suffer from distress, low spiritual well-being, and low quality of life; furthermore, the findings serve to inform the international cultural adaptation efforts of MCP.

The results indicate that MCP needs modifications (e.g. simplifying content, present examples, brief definitions, and shorter questions) in the intervention and focus on cultural content. Therefore, this research shows that many of the concepts had a high acceptance; however, they should be organized and presented in a more understandable manner for patients. Simplifying the content for clarity presents a challenging but necessary step in the cultural adaptation process, since it will improve the "delivery" of the MCP terms in a comprehensible manner. Yet special attention must be taken to safeguard the validity of the original model. To account for patient's low literacy levels and to improve comprehension, the content should include examples, shorter questions, and brief definitions of the central MCP concepts $[41,42]$.

In this study, the majority of participants had lower levels of education ( $<$ High School) and demonstrated a low or moderate comprehension of the following concepts: legacy, finite, identity, and connective with life. As it can be observed, the concepts in which the participants showed low and moderate comprehension are concepts that require more abstraction on the part of the participants. This is consistent with what is presented in the cultural adaptation of a Cognitive Behavioral Therapy intervention for people with poor literacy [42].

As initially reported by semi-structured interviews with key informants and comments through the ethnographic notes, the treatment should be further simplified by incorporating the cognitive load theory guidelines established by several health literacy researchers [43]. Thorn and colleagues [42] worked on recommendations when treatment required a high cognitive demand. For example, in his case, Cognitive Behavioral Therapy. Before each task, a flip chart was utilized during the session to facilitate interaction that provided examples of patients.

The technique of examples and flipcharts reduces the cognitive demand of the activity, and facilitates the ability of members to complete the task between sessions [44]. Additional recommendations to reduce cognitive demand according to Davis et al. [43] included the elimination of distractors, the use of repetition, the limitation of the amount of information given, the use of "teaching" methods to confirm comprehension, and teaching to ensure mastery of learning [44]. Therefore, this could be an excellent recommendation to include in later works involving the cultural adaptation of MCP.

Also, there is a need to provide psychoeducation to providers and patients on the importance of addressing death and improving the cultural acceptability of MCP concepts (e.g. connecting with life) and Culturally relevant values (e.g., family). The study's data are consistent with the 
literature documenting fear and anxiety as the main barriers that prevent cancer patients from seeking information [45]. The anguish caused by a cancer diagnosis often hinders patients from withholding information related to cancer or asking questions at the time of diagnosis [43]. Although fear can be considered a universal reaction to a cancer diagnosis, it can be mitigated by understanding the course of the disease and gaining appropriate support for decision-making about treatment [45].

Future studies on MCP should explore the role and influence of family caregivers on the adjustment of patients and adapt MCP for the family [46, 47]. As the number of cancer diagnoses increases, FCs play an essential role in providing care throughout the trajectory of the disease. Significant numbers of advanced cancer patients and their families emphasize the need for increased attention to end-of-life care [48]. In our pervious preliminary study data, the $86 \%$ of the Latino advanced cancer patients report low family functioning; studies suggest that low family functioning negatively impacts cancer illness trajectory [48, 49, 50, 51, 52]. The World Health Organization, The Institute of Medicine, and the American Society of Clinical Oncology emphasized the importance of improving quality of life of patients and their FCs as an essential component of cancer care $[53,54,55]$. High-quality end-of-life care includes addressing the emotional needs of FCs, including burden, spiritual, and existential needs.

\section{Conclusion}

The present study is the beginning of the cultural adaptation of MCP intervention in Puerto Rican patients with advanced cancer as part of a larger project led by Dr. Rosario Costas. Our findings not only confirm that the use of MCP is a psychotherapeutic intervention that can be used for the Puerto Rican population, but has also been shown to be understood and accepted by Puerto Rican cancer patients with advanced diagnoses. This is the first step in the cultural adaptation process, which provides an ideal balance between incorporating the Puerto Rican cultural context and maintaining the integrity of the intervention. Additional studies are needed to address cultural themes to improve comprehension of the central MCP concepts.

\section{Acknowledgements}

We would like to acknowledge the contribution (2U54CA163071 and 2U54CA163068) and the National Institute of Minority Health and Health Disparities (U54MD007579, 5G12MD007579，5R25MD007607, and R21MD013674); National Cancer Institute R21CA180831-02 (Cultural Adaptation of Meaning-Centered Psychotherapy for Latinos), and the Memorial Sloan Kettering Cancer Center grant (P30CA008748). Supported in part by 133798-PF-19-120-01-CPPB from the American Cancer Society.

\section{References}

[1] Bishaw A, Fontenot K. Poverty: 2012 and 2013, American community survey briefs. Washington, DC: US Census Bureau. 2014.

[2] O'Neil ME, Henley SJ, Singh SD, Wilson RJ, Ortiz-Ortiz KJ, Ríos NP, Cintrón CR, Luna GT, Zegarra DE, Ryerson AB. Invasive Cancer Incidence-Puerto Rico, 2007-2011. MMWR. Morbidity and mortality weekly report. 2015 Apr 17; 64 (14): 389.

[3] Costas R, Gany F. Depressive symptoms in a sample of Afro-Caribbean and Latino immigrant cancer patients: a comparative analysis. Support Care Cancer. 2013; 21 (9): 2461-2468.

[4] Luckett T, Goldstein D, Butow PN, et al. Psychological morbidity and quality of life of ethnic minority patients with cancer: a systematic review and meta-analysis. Lancet Oncol. 2017; $\quad 12 \quad$ (13): 1240-1248. doi: $10.1016 / \mathrm{S} 1470-2045(11) 70212-1$.

[5] Breitbart W, Poppito S, Rosenfeld B, Vickers AJ, Li Y, Abbey J, Olden M, Pessin H, Lichtenthal W, Sjoberg D, Cassileth BR. Pilot randomized controlled trial of individual meaning-centered psychotherapy for patients with advanced cancer. Journal of Clinical Oncology. 2012 Apr 20; 30 (12): 1304.

[6] Lo C, Hales S, Jung J, Chiu A, Panday T, Rydall A, Nissim R, Malfitano C, Petricone-Westwood D, Zimmermann C, Rodin G. Managing Cancer And Living Meaningfully (CALM): phase 2 trial of a brief individual psychotherapy for patients with advanced cancer. Palliative medicine. 2014 Mar; 28 (3): 234-42.

[7] Northouse LL, Mood DW, Schafenacker A, Kalemkerian G, Zalupski M, LoRusso P, Hayes DF, Hussain M, Ruckdeschel J, Fendrick AM, Trask PC. Randomized clinical trial of a brief and extensive dyadic intervention for advanced cancer patients and their family caregivers. Psycho-Oncology. 2013 Mar; 22 (3): $555-63$.

[8] Liossi C, White P. Efficacy of clinical hypnosis in the enhancement of quality of life of terminally ill cancer patients. Contemporary Hypnosis. 2001 Sep; 18 (3): 145-60.

[9] do Carmo TM, Paiva BS, de Oliveira CZ, de Angelis Nascimento MS, Paiva CE. The feasibility and benefit of a brief psychosocial intervention in addition to early palliative care in patients with advanced cancer to reduce depressive symptoms: a pilot randomized controlled clinical trial. BMC cancer. 2017 Dec; 17 (1): 564.

[10] Prescott AT, Hull JG, Dionne-Odom JN, Tosteson TD, Lyons KD, Li Z, Li Z, Dragnev KH, Hegel MT, Steinhauser KE, Ahles TA. The role of a palliative care intervention in moderating the relationship between depression and survival among individuals with advanced cancer. Health Psychology. 2017 Dec; 36 (12): 1140.

[11] Triplett DP, LeBrett WG, Bryant AK, Bruggeman AR, Matsuno RK, Hwang L, Boero IJ, Roeland EJ, Yeung HN, Murphy JD. Effect of palliative care on aggressiveness of end-of-life care among patients with advanced cancer. Journal of oncology practice. 2017 Aug 22; 13 (9): e760-9. 
[12] Nottelmann L, Groenvold M, Vejlgaard TB, Petersen MA, Jensen LH. A parallel-group randomized clinical trial of individually tailored, multidisciplinary, palliative rehabilitation for patients with newly diagnosed advanced cancer: the Pal-Rehab study protocol. BMC cancer. 2017 Dec; 17 (1): 560.

[13] Nipp RD, Greer JA, El-Jawahri A, Moran SM, Traeger L, Jacobs JM, Jacobsen JC, Gallagher ER, Park ER, Ryan DP, Jackson VA. Coping and Prognostic Awareness in Patients With Advanced Cancer. Journal of clinical oncology: official journal of the American Society of Clinical Oncology. 2017 Aug; 35 (22): 2551-7.

[14] Hoek PD, Schers HJ, Bronkhorst EM, Vissers KC, Hasselaar JG. The effect of weekly specialist palliative care teleconsultations in patients with advanced cancer-a randomized clinical trial. BMC medicine. 2017 Dec; 15 (1): 119.

[15] Epstein AS, O'Reilly EM, Shuk E, Breitbart W, Shah MA, Ly M, Tayler R, Volandes AE. Development of an advance care planning paradigm for advanced cancer: person-centered oncologic care and choices (P-COCC). Psycho-oncology. 2017 Jun; 26 (6): 866.

[16] Kissane DW, Zaider TI, Li Y, Hichenberg S, Schuler T, Lederberg M, Lavelle L, Loeb R, Del Gaudio F. Randomized controlled trial of family therapy in advanced cancer continued into bereavement. Journal of clinical oncology. 2016 Jun 1; 34 (16): 1921.

[17] Breitbart W, Pessin H, Rosenfeld B, Applebaum AJ, Lichtenthal WG, Li Y, Saracino RM, Marziliano AM, Masterson M, Tobias K, Fenn N. Individual meaning-centered psychotherapy for the treatment of psychological and existential distress: A randomized controlled trial in patients with advanced cancer. Cancer. 2018 Aug 1; 124 (15): 3231-9.

[18] Greer JA, Jacobs JM, El-Jawahri A, Nipp RD, Gallagher ER, Pirl WF, Park ER, Muzikansky A, Jacobsen JC, Jackson VA, Temel JS. Role of Patient Coping Strategies in Understanding the Effects of Early Palliative Care on Quality of Life and Mood. Journal of clinical oncology: official journal of the American Society of Clinical Oncology. 2018 Jan; 36 (1): 53-60.

[19] Serfaty M, King M, Nazareth I, Tookman A, Wood J, Gola A, Aspden T, Mannix K, Davis S, Moorey S, Jones L. The clinical and cost effectiveness of cognitive behavioural therapy plus treatment as usual for the treatment of depression in advanced cancer (CanTalk): study protocol for a randomised controlled trial. Trials. 2016 Dec; 17 (1): 113.

[20] Chambers SK, Occhipinti S, Foley E, Clutton S, Legg M, Berry M, Stockler MR, Frydenberg M, Gardiner RA, Lepore SJ, Davis ID. Mindfulness-based cognitive therapy in advanced prostate cancer: a randomized controlled trial. Journal of Clinical Oncology. 2016 Nov 21; 35 (3): 291-7.

[21] Feldstain A, Lebel S, Chasen MR. An interdisciplinary palliative rehabilitation intervention bolstering general self-efficacy to attenuate symptoms of depression in patients living with advanced cancer. Supportive Care in Cancer. 2016 Jan 1; 24 (1): 109-17.

[22] Rosenfeld B, Cham H, Pessin H, Breitbart W. Why is Meaning-Centered Group Psychotherapy (MCGP) effective? Enhanced sense of meaning as the mechanism of change for advanced cancer patients. Psycho-Oncology. 2018 Feb; 27 (2): 654-60.
[23] Hunter-Hernández M, Costas-Muñíz R, Gany F. Missed opportunity: spirituality as a bridge to resilience in Latinos with cancer. Journal of religion and health. 2015 Dec 1; 54 (6): 2367-75.

[24] Page AE, Adler NE, editors. Cancer care for the whole patient: Meeting psychosocial health needs. National Academies Press; 2008 Apr 19.

[25] Carlson LE, Waller A, Mitchell AJ. Screening for distress and unmet needs in patients with cancer: review and recommendations. Journal of Clinical Oncology. 2012 Mar 12; 30 (11): 1160-77.

[26] Molina Y, Yi JC, Martinez-Gutierrez J, Reding KW, Yi-Frazier JP, Rosenberg AR. Resilience among patients across the cancer continuum: diverse perspectives. Clin J Oncol Nurs. 2014; 18 (1): 93-101. doi: 10.1188/14.CJON.93-101.

[27] Yanez B, Thompson EH, Stanton AL. Quality of life among Latina breast cancer patients: a systematic review of the literature. Journal of Cancer Survivorship. 2011 Jun 1; 5 (2): 191-207.

[28] Lee MS, Tyson DM, Gonzalez BD, Small BJ, Lechner SC, Antoni MH, Vinard A, Krause M, Meade C, Jacobsen PB. Anxiety and depression in Spanish-speaking Latina cancer patients prior to starting chemotherapy. Psycho-oncology. 2018 Jan; 27 (1): 333-8.

[29] Bai M, Lazenby M. A systematic review of associations between spiritual well-being and quality of life at the scale and factor levels in studies among patients with cancer. Journal of palliative medicine. 2015 Mar 1; 18 (3): 286-98.

[30] Breitbart W, Rosenfeld B, Gibson C, Pessin H, Poppito S, Nelson C, Tomarken A, Timm AK, Berg A, Jacobson C, Sorger B. Meaning-centered group psychotherapy for patients with advanced cancer: a pilot randomized controlled trial. Psycho-oncology. 2010 Jan 1; 19 (1): 21-8.

[31] Breitbart W, Rosenfeld B, Pessin H, Applebaum A, Kulikowski J, Lichtenthal WG. Meaning-centered group psychotherapy: an effective intervention for improving psychological well-being in patients with advanced cancer. Journal of Clinical Oncology. 2015 Mar 1; 33 (7): 749.

[32] Bernal G, Bonilla J, Bellido C. Ecological validity and cultural sensitivity for outcome research: Issues for the cultural adaptation and development of psychosocial treatments with Hispanics. Journal of abnormal child psychology. 1995 Feb 1; 23 (1): 67-82.

[33] Bernal G, Sáez-Santiago E. Culturally centered psychosocial interventions. Journal of Community Psychology. 2006 Mar; 34 (2): 121-32.

[34] Bernal GE, Domenech Rodríguez MM. Cultural adaptations: Tools for evidence-based practice with diverse populations. American Psychological Association; 2012.

[35] Rosselló J, Bernal G. The efficacy of cognitive-behavioral and interpersonal treatments for depression in Puerto Rican adolescents. Journal of Consulting and clinical Psychology. 1999 Oct; 67 (5): 734.

[36] Matos M, Torres R, Santiago R, Jurado M, Rodríguez IX. Adaptation of parent-child interaction therapy for Puerto Rican families: A preliminary study. Family Process. 2006 Jun; 45 (2): 205-22. 
[37] Creswell JW, Klassen AC, Plano Clark VL, Smith KC. Best practices for mixed methods research in the health sciences. Bethesda (Maryland): National Institutes of Health. 2011 Aug 1; 2013: 541-5.

[38] Almanza-Muñoz JD, Juárez IR, Pérez S. Traducción, adaptación y validación del Termómetro de Distrés en una muestra de pacientes mexicanos con cáncer. Revista De Sanidad Militar. 2008; 62 (5): 209-17.

[39] Murphy PE, Canada AL, Fitchett G, Stein K, Portier K, Crammer C, Peterman AH. An examination of the 3-factor model and structural invariance across racial/ethnic groups for the FACIT-Sp: a report from the American Cancer Society's Study of Cancer Survivors-II (SCS-II). Psycho-Oncology: Journal of the Psychological, Social and Behavioral Dimensions of Cancer. 2010 Mar; 19 (3): 264-72.

[40] Dapueto JJ, Francolino C, Servente L, Chang CH, Gotta I, Levin R, del Carmen Abreu M. Evaluation of the Functional Assessment of Cancer Therapy-General (FACT-G) Spanish Version 4 in South America: classic psychometric and item response theory analyses. Health and quality of life outcomes. 2003 Dec; 1 (1): 32.

[41] Schaffler J, Leung K, Tremblay S, Merdsoy L, Belzile E, Lambrou A, Lambert SD. The effectiveness of self-management interventions for individuals with low health literacy and/or low income: a descriptive systematic review. Journal of general internal medicine. 2018 Apr 1; 33 (4): 510-23.

[42] Thorn BE, Day MA, Burns J, Kuhajda MC, Gaskins SW, Sweeney K, McConley R, Ward LC, Cabbil C. Randomized trial of group cognitive behavioral therapy compared with a pain education control for low-literacy rural people with chronic pain. Pain. 2011 Dec 1; 152 (12): 2710-20.

[43] Davis TC, Williams MV, Marin E, Parker RM, Glass J. Health literacy and cancer communication. CA: a cancer journal for clinicians. 2002 May; 52 (3): 134-49.

[44] Wolf MS, Davis TC, Osborn CY, Skripkauskas S, Bennett CL, Makoul G. Literacy, self-efficacy, and HIV medication adherence. Patient education and counseling. 2007 Feb 1; 65 (2): 253-60.

[45] Biedrzycki BA. Factors and outcomes of decision making for cancer clinical triaparticipation. InOncology nursing forum 2011 Sep 1 (Vol. 38, No. 5).
[46] Applebaum AJ, Breitbart W. Care for the cancer caregiver: a systematic review. Palliative \& supportive care. 2013 Jun; 11 (3): 231-52.

[47] Applebaum AJ, Kulikowski JR, Breitbart W. Meaning-centered psychotherapy for cancer caregivers (MCP-C): Rationale and overview. Palliative \& supportive care. 2015 Dec; 13 (6): 1631-41.

[48] Lim SM, Kim HC, Lee S. Psychosocial impact of cancer patients on their family members. Cancer research and treatment: official journal of Korean Cancer Association. 2013 Sep; 45 (3): 226.

[49] Peppercorn JM, Smith TJ, Helft PR, DeBono DJ, Berry SR, Wollins DS, Hayes DM, Von Roenn JH, Schnipper LE. American society of clinical oncology statement: toward individualized care for patients with advanced cancer. J Clin Oncol. 2011 Feb 20; 29 (6): 755-60.

[50] Harding R, Higginson IJ. What is the best way to help caregivers in cancer and palliative care? A systematic literature review of interventions and their effectiveness. Palliative medicine. 2003 Jan; 17 (1): 63-74.

[51] McCorkle R, Siefert ML, Dowd MF, Robinson JP, Pickett M. Effects of advanced practice nursing on patient and spouse depressive symptoms, sexual function, and marital interaction after radical prostatectomy. Urologic Nursing. 2007 Feb 1; 27 (1): 65 .

[52] Northouse LL, Mood D, Templin T, Mellon S, George T. Couples' patterns of adjustment to colon cancer. Social science \& medicine. 2000 Jan 1; 50 (2): 271-84.

[53] Powell RA, Mwangi-Powell FN, Radbruch L, Yamey G, Krakauer EL, Spence D, Ali Z, Baxter S, De Lima L, Xhixha A, Rajagopal MR. Putting palliative care on the global health agenda. The Lancet Oncology. 2015 Feb 1; 16 (2): 131-3.

[54] Smith TJ, Temin S, Alesi ER, Abernethy AP, Balboni TA, Basch EM, Ferrell BR, Loscalzo M, Meier DE, Paice JA, Peppercorn JM. American Society of Clinical Oncology provisional clinical opinion: the integration of palliative care into standard oncology care. Journal of clinical oncology. 2012 Feb 6; 30 (8): 880-7.

[55] Levit LA, Balogh E, Nass SJ, Ganz P, editors. Delivering high-quality cancer care: charting a new course for a system in crisis. Washington, DC: National Academies Press; 2013 Sep. 